\title{
Psychometric performance of the Brazilian version the “Insulin Management Diabetes Self-Efficacy Scale” for patient with Type 2 Diabetes Mellitus
}

\author{
Propriedades psicométricas da versão brasileira "Escala de auto-eficácia no manejo da \\ insulina" em pacientes com diabetes mellitus tipo 2
}

Rafaela Batista dos Santos Pedrosa ${ }^{1}$, Danilo Donizetti Trevisan'2, Renata Aparecida do Nascimento3, Thaís Moreira São-João', Maria Helena de Melo Lima', Roberta Cunha Matheus Rodrigues ${ }^{4}$

\begin{abstract}
Model of study: Validation study.

Objective: To evaluate the psychometric performance of the Brazilian version of the Insulin Management Diabetes Self-Efficacy Scale - IMDSES.

Methodology: Reliability (internal consistency - Cronbach's $\alpha$ ), convergent and criterion validity were assessed. Data were gathered from 127 patients with type 2 diabetes mellitus (T2DM) in use of insulin through the application of sociodemographic and clinical instruments and the Brazilian versions of the Summary of Diabetes Self-Care Activities Measures - SDSCA and the IMDSES.

Results: It was observed "ceiling effect" in Insulin domain. Reliability was confirmed in all IMDSES domains and Total Score $(\alpha=0.87)$. The convergent construct validity was supported by significant negative moderate to weak magnitude correlations between the scores of IMDSES domains and the scores of SDSCA domains. Criterion validity was partially supported by the weak magnitude correlation between the General Managements domain and the Total Score of IMDSES and serum levels of glycated hemoglobin ( $r=0.22 ; p=0.02)$.

Conclusion: The Brazilian version of IMDSES presented satisfactory psychometric measures and may be useful to evaluate the effectiveness of nursing interventions aimed at optimizing the self-efficacy of the T2DM patient in the management of his treatment.
\end{abstract}

Keywords: Type 2 Diabetes Mellitus. Self Efficacy. Validation Studies. Nursing. Questionnaires. Psychometric Properties.

1. Registered Nurse (RN), Ph.D Universidade de Cam-pinas, Faculdade de Enfermagem. Campinas, SP

2. RN, PhD, Professor. Universidade Federal de São João Del-Rei, Campus de Divinópolis, MG, Brasil.

3. RN, Universidade de Campinas, Faculdade de Enfermagem. Campinas, SP, Brasil.

4. RN, PhD, Professor. Universidade de Campinas, Faculdade de Enfermagem. Campinas, SP, Brasil.

Disclosure of potential conflicts of interest: The authors have no conflicts of interest to disclose.
CoRrespondencia: Universidade de Campinas, Faculdade de Enfermagem Rua Tessália Vieira de Camargo, 126. Cidade Universitária Zeferino Vaz Barão Geraldo. 13083-970 - Campinas - SP. Brasil

Recebido em 09/11/2017 Aprovado em 26/06/2018 


\begin{abstract}
RESUMO
Modelo de estudo: estudo de validação.

Objetivo: Avaliar o desempenho psicométrico da versão brasileira "Escala de Auto-eficácia no manejo da insulina" - IMDSES.

Metodologia: A confiabilidade (consistência interna - a Cronbach), a validade convergente e a validade de critério foram avaliadas. Os dados foram coletados de 127 pacientes com diabetes mellitus tipo 2 (DM2) em uso de insulina por meio da aplicação de instrumentos sociodemográficos e clínicos e as versões brasileiras "Summary of Diabetes Self-Care Activities Measures" - SDSCA and the IMDSES.
\end{abstract}

Resultados: Observou-se "efeito de teto" no domínio da insulina. A confiabilidade foi confirmada em todos os domínios do IMDSES obtendo pontuação total satisfatória $(\alpha=0,87)$. A validade con-vergente de constructo foi confirmada por correlações negativas significativas de magnitude mo-derada a fraca entre os escores dos domínios do IMDSES e os escores de domínio da SDSCA. A validade de critério foi parcialmente confimada por correlação de magnitude fraca entre o domí-nio de Gerenciamento Geral e o escore total do IMDSES e níveis de hemoglobina glicada $(r=0.22 ; p=0.02)$.

Conclusão: A versão brasileira do IMDSES apresentou medidas psicométricas satisfatórias e pode ser útil para avaliar a efetividade das intervenções de enfermagem que visam otimizar a autoeficácia do paciente com DM2 no manejo do tratamento.

Palavras-chave: Diabetes Mellitus Tipo 2. Autoeficácia. Estudos de Validação. Enfermagem. Questionários. Propriedades Psicométricas.

\section{INTRODUCTION}

As a chronic condition, Type 2 Diabetes mellitus (T2DM) requires the individual to adopt complex practices to control its progression and prevent its complications. ${ }^{1}$ One of the strategies used to adopt healthy practices is to improve pa-tient confidence in their capacity/ability to perform the behavior, that is, the improvement of their selfefficacy (SE). ${ }^{2}$ SE, a central construct of Social Cognitive Theory, can be defined as the individual's perception of their ability to organize and perform certain actions to achieve a target outcome. ${ }^{2}$

A high SE is needed in order to obtain a personal wellness effect aimed at adopting positive behaviors, considering that the higher the individual conviction of the ability to produce desired results, the more intense and lasting will be the attempt to deal with the challenges inherent behavioral changes. ${ }^{3}$ The relationship between SE and adoption of health behaviors has been investigated in numerous studies which suggest that the strengthening of SE relates to the adoption of health practices in different clinical conditions $\mathrm{s}^{4,5}$ and among those with Diabetes mellitus (DM). ${ }^{6-} 10$ Regarding T2DM, SE has been considered an important outcome measure of self-manage-ment interventions. ${ }^{11}$ In this sense, studies of pa-

122 tients with T2DM demonstrated that greater SE predicted better nutrition and medication management, more frequent self-monitoring of blood glucose and enhanced physical activity. While higher levels of SE have been considered indicator of better diabetes control, lower levels have been seen as an indicator of worse diabetes control. ${ }^{12}$ Aimed at evaluating the relationship be-

tween SE and the best performance by people with T2DM in adopting healthy behaviors, differ-ent instruments that measure how capable the individual perceives himself to play their care plan were created. ${ }^{13,14,15}$ Among them, the Insulin Man-agement Diabetes Self-efficacy Scale (IMDSES), ${ }^{16}$ developed in the United States to measure SE of adults with diabetes (type 1 and 2) specific for those treated with insulin. Thus, the aim of this study was to expand the evaluation of the psy-chometric properties of the Brazilian version of IMDSES through its use in patients with type 2 diabetes mellitus.

\section{METHOD}

\subsection{Study design and Setting}

This methodological study was conducted in a Primary care Unit and in a specialized outpa- 
tient clinic of DM of a city university hospital in the Campinas, state of São Paulo, Brazil. Data collection was carried out between May and Octo-ber of 2012.

All procedures performed in studies involving human participants were in accordance with the ethical standards of the institutional and/or national research committee and with the 1964 Helsinki declaration; as well as its later amendments or comparable ethical standards. The study was approved by the local research ethics committee (No.1180/2011).

\subsection{Sample selection and data collection}

All patients (age $>18$ years) with T2DM insulin applicants were included in outpatient monitoring. The exclusion criteria were: patients us-ing insulin for at least one year, who had chronic complications in the advanced stage as those with chronic renal failure diagnosis on hemodialysis, blindness, heart failure class III and IV and/or motor sequel of stroke were excluded.

The interviews were carried out individually by means of a patient approach in a private setting and consultation with available data in the registries. The sociodemographic and clinical data were obtained and Brazilian versions of the Summary of Diabetes Self-Care Activities Measures were applied - SDSCA and IMDSES 28 through interviews. This alteration of data gathering technique has been performed elsewhere with no harms to participants or the instrument psychometric performance. ${ }^{17}$

To estimate the sample size, data from a pilot study among 20 subjects were used. Then sample size was calculated based on the Pearson correlation coefficient, considering as the null hypothesis, correlation coefficient $=0$ (zero), $\alpha=$ 0.05 and $\beta=88 \%$. The correlation coefficients were considered among the IMDSES Total Score and the domains of Specific Food and Glucose Moni-toring Summary of SDSCA, estimating the sample size of 127 subjects.

\subsection{Measurement}

Insulin Management Diabetes Self-Efficacy Scale (IMDSES): the original American version consists of 28 items that measure self-effi- cacy for seven behaviors: General Management, Diet, Exercise, Feet care, blood glucose monitoring, insulin administration and Prevention, Detection and Treatment of Hypoglycemia/Hyperglycemia. The answers are rated on a Likert-type scale of six points with the possibility of a "not apply" answer. ${ }^{16,18}$ The cultural adaptation of IMDSES 28-items for the Brazilian context 17 was conducted in subjects with type 1 diabetes mellitus, dependent on insulin, and it has been modified from the original scale. The Likert-type response scale of six points has been changed to four-point and maintained the possibility of a fifth alternative "do not apply". Thus, the Brazil-ian version of IMDSES consists of 20 items distributed in the domains - General Management, Diet and Insulin. In this study we chose to use the Brazilian version of IDMSES with 28 items, without excluding the eight items proposed by Gastal, Pinheiro, and Vazquez. ${ }^{17}$ The calculation of the total score corresponds to the average of the scores, with a possible variation of 28 up to 112. The higher the score, the lower the self-efficacy. Item 13 (drafted in the negative) needs reverse scoring for calculating the total score.

\section{Summary of Diabetes Self-Care Activities}

Measures (SDSCA): the scale built to assess the level of self-care in patients with T2DM, in the last seven days, consists of 11 items by measuring six domains: General Diet, Specific Diet, Physical Activity, Blood Glucose Monitoring, Feet Care and Tobacco. Also, additional items were included re-lated to self-care recommendations (expanded version)

that are not accounted for score calcu-lating. ${ }^{19}$ The adaptation of expanded SDSCA into the Brazilian context was also conducted in pa-tients with T2DM. ${ }^{20}$ It was chosen in the Brazilian version by the inclusion of items in the expanded version, as an item of Feet Care, items on Medi-cation and Tobacco. Thus, the Brazilian version of SDCSA consists of 15 self-care assessment items in six domains: General Diet, Specific Diet, Physi-cal Activity, Glucose Monitoring, Feet Care and medication; plus three additional items for Tobacco assessment. The score is obtained for each dimen-sion by the average number of days (scale 0-7), zero being the least desirable and seven to the more favorable situation. 


\subsection{Data Analysis}

The statistical software program SAS ("Statistical Analysis System") version 9.2 was used for the following analyses:

- Descriptive analysis of sociodemographic and clinical variables and the scores of the domains and the total score of the Brazilian version of the IMDSES and SDSCA;

- Ceiling and floor effects: floor effect of IMDSES 28-item was evaluated by the percentage of patients who scored the $10 \%$ worse possible results of the scale). Ceiling effect was evaluated by the percentage of patients who rated the $10 \%$ best possible results of the scale; ${ }^{21}$

- Practicability: assessed by time spent in the in-strument application;

- Acceptability: evaluated by the percentage of patients who responded all items;

- Reliability regarding internal consistency: estimated using Cronbach's alpha coefficient. Satisfactory internal consistency $\alpha>0.70$ was considered; ${ }^{22}$

- Convergent Construct Validity: assessed through the use of the Spearman correlation coefficient to test the scores of the Brazilian version of the IMDSES and of the SDSCA. In order to test convergent validity, moderate to strong magnitude correlations were hypothesized between simi-lar constructs of IMDSES and SDCDA domains and no correlation or weak magnitude correla-tions were hypothesized between dissimilar constructs;

- Predictive Criterion Validity: assessed by the Spearman correlation coefficient to test the correlation between the IMDSES and the value of serum glycated hemoglobin (HbA1c) - one of the indicators considered "gold standard" in glycemic control. To test the validity criterion, moderate to strong magnitude negative correlations were hypothesized between IMDSES Total score and serum levels of glycated hemoglobin.

For the interpretation of the magnitude of the correlation coefficients, the criteria adopted by Fishbein and Ajzen $^{23}$ was used, which considers correlations $\leq 0.30$ of low magnitude, from 0.31 up to 0.50 of moderate magnitude and $>0.5$ of strong magnitude. A significance level of $5 \%$ was adopted.

\section{RESULTS}

It was found a predominance of women $(59.8 \%)$ with a mean age of $58.3(\mathrm{SD}=9.3)$ years old, with an average schooling of 6.1 (SD = 4.6) years. The average length of diagnosis of $D M$ was of 15.1 ( $S D=9.3$ ) years and the mean duration of treatment with insulin was 7.7 (SD = 6.6) years. Among the associated clinical conditions, hyper-tension (85.2\%), metabolic syndrome $(83.5 \%)$, obesity $(80 \%)$ and dyslipidemia (71.8\%) were highlighted. The mean of the HbA1c was $9.0 \%(S D=2.1)$.

3.1 Analysis of the practicability, acceptability, ceiling and floor effects and descriptive measures of the Brazilian version of the

\section{IMDSES}

\section{Practicability}

As for the practicability of IMDSES, there was an average application time of 21.7 (SD = 10.4) minutes.

\section{Acceptability}

Regarding acceptability, all patients responded to all of the items.

\section{Ceiling and floor effects}

In the analysis of ceiling and floor effects, assessing the proportion of $10 \%$ of the best and worst possible score of the scale, there was no floor effect for domains and Total Score. A ceiling effect was observed in the Insulin domain of the IMDSES, that is, $18.9 \%$ of participants scored in the best possible scale score in this domain.

\section{Descriptive analysis}

It has been found for the three domains of the Brazilian version of IMDSES as well as for the Total Score; scores above the possible averages, which indicates the self-efficacy level of commitment of the interviewees. The General Management domain had less involvement of self-efficacy level with an average of $2.3(S D=0.3$ ) while the Insulin domain had the greater average commitment of 3.0 (SD = 0.5). The analysis of data on SDSCA shows score below the average expected for all domains, especially for Specific diet (3.7), showing a low level of self-care (see Table 1 ). 
Table 1

Descriptive analysis of domains and total score of the Brazilian version of the Insulin Management Diabetes SelfEfficacy Scale - IMDSES 28-items and the Summary of Diabetes Self-Care Activities Measures - SDSCA ( $n=127$ ).

\begin{tabular}{|c|c|c|c|c|c|c|c|}
\hline \multirow{2}{*}{$\begin{array}{l}\text { IMDSES domains } \\
\text { Diet }\end{array}$} & \multirow{2}{*}{$\begin{array}{r}\text { Number } \\
\text { of items } \\
08\end{array}$} & \multicolumn{2}{|c|}{$\begin{array}{c}\text { Average } \\
\left(\mathrm{SD}^{*}\right)\end{array}$} & \multirow{2}{*}{$\begin{array}{c}\text { Median } \\
2.5\end{array}$} & \multirow{2}{*}{$\begin{array}{c}\begin{array}{c}\text { Variation } \\
\text { observed }\end{array} \\
1.7-3.5\end{array}$} & \multirow{2}{*}{$\begin{array}{c}\begin{array}{c}\text { Floor } \\
\text { Effect } \\
(\%)\end{array} \\
0.0\end{array}$} & \multirow{2}{*}{$\begin{array}{r}\text { Ceiling } \\
\text { Effect } \\
(\%) \\
0.0\end{array}$} \\
\hline & & 2.5 & $(0.3)$ & & & & \\
\hline Insulin & 05 & 3.0 & $(0.5)$ & 3.0 & $2.0-4.0$ & 0.0 & 18.9 \\
\hline General Management & 15 & 2.3 & $(0.3)$ & 2.3 & $1.4-2.5$ & 0.0 & 0.0 \\
\hline IMDSES - Total & 28 & 2.5 & $(0.3)$ & 2.5 & $1.8-2.7$ & 0.0 & 0.0 \\
\hline \multicolumn{8}{|l|}{ SDSCA domains } \\
\hline General diet & 02 & 4.1 & $(2.4)$ & 4.0 & $0.0-7.0$ & 13.4 & 27.5 \\
\hline Specific diet & 03 & 3.7 & $(1.4)$ & 3.7 & $0.0-6.7$ & 1.6 & 5.5 \\
\hline Physical activity & 02 & 1.1 & $(2.1)$ & 0.0 & $0.0-7.0$ & 74.8 & 8.7 \\
\hline Glucose monitoring & 02 & 4.7 & $(2.6)$ & 6.0 & $0.0-7.0$ & 12.6 & 47.2 \\
\hline Feet care & 03 & 4.5 & $(2.7)$ & 4.7 & $0.0-7.0$ & 19.0 & 42.0 \\
\hline Medication & 03 & 6.8 & $(0.9)$ & 7.0 & $2.3-7.0$ & 0.0 & 92.1 \\
\hline
\end{tabular}

\subsection{Reliability Analysis}

The reliability regarding internal consistency of the IMDSES was measured through Cronbach's alpha coefficient (a) estimation. Considering satisfactory internal consistency as $\alpha>$

0.70 Cronbach's alpha 22 was satisfactory for all the IMDSES domains and for the Total Score. The analysis of item-total correlation and Cronbach's alpha if the item is deleted showed that in the Diet domain, coefficient lift to the exclusion of items 1 and 10. In the General Management domain, it was found higher coefficients with the exclusion of items 12, Item 13 and 27 (see Table 2).

\subsection{Convergent Construct Validity}

The convergent construct validity was assessed by the correlation between the Total score and domains of the Brazilian version of IMDSES and the scores obtained by the application of SDSCA. Data evidences that the Diet domain of IMDSES showed a negative correlation of moder- ate magnitude with the General Diet domain ( $r=-$ $0.40 ; p<0.0001)$ and low magnitude of correlation with the Specific Diet domains $(r=-0.27$ $p<0.0001)$, Feet Care $(r=-0.29 ; p<0.0001)$ and medication $(r=-0.26 ; p<0.0001)$ of SDSCA. The domain General Management of IMDSES also showed moderate correlation with the Feet Care domain $(r=-0.33 ; p<0.0001)$ and low magnitude of correlation with the domain General Diet, Specific Diet and Physical Activity of the SDSCA. It appears that the Insulin domain of IMDSES presented a single weak correlation magnitude with the Feet Care domain of SDSCA ( $r=-0.24$; $\mathrm{p}<0.0001)$. The other correlations were considered significant although with tiny practical value.

In turn, the total score of IMDSES correlated with moderate magnitude with the Feet Care domain $(r=-0.39 ; p<0.0001)$ and significant correlations of weak magnitude with other domains of SDSCA, except to the domains Blood Glucose Moni-toring and Medication, for which correlations were observed with the Total Score of IMDSES (see Table 3). 


\section{Table 2}

Correlation item-total, Cronbach's alpha coefficients, and Cronbach's alpha if the item is deleted from the Brazilian version of Insulin Management Diabetes Self-Efficacy Scale - IMDSES 28-items ( $n=127)$.

Cronbach's Alpha

IMDSES Scale

Item-total Cronbach's (if the item

Diet correlation Alpha

Item 1 I can carry out most of the time, treatment of diabetes

0.71

in my everyday life. For example, applying insulin,

$-0.001$

0.732 do the diet.

Item 5 Can I dine at the same time every day?

$0.095-0.702$

$\overline{\text { Item } 6}$ I can keep my diet when I eat out in known locations

0.356

0.639 (for example, Friends)?

Item 7 Can I keep my diet when I make meals away from

0.356

0.640 home, in unfamiliar places?

Item 8 Am I sure, I will be able to keep my diet when people

0.596 around me do not know that I am diabetic?

Item 9 Am I sure, I can keep my diet every day?

0.452

0.673

Item 10 Can I correctly replace one type of food for another from the same group? For example: Changing rice for potatoes (or other food of the same group)

Item 11 Can I keep my diet when I go to parties?

Insulin

Item 22

I can adjust me a dose of insulin based on the results

0.94 of sugar in blood or urine tests, when necessary

Item 23 I am sure I can adjust my insulin dose, when changes in my daily routine (some change that I am used to doing every day)?

Item 24 Do I know how to adjust my insulin dose to avoid sugar crash when practicing physical exercise?

Item 25 I know what kind of adjustment in insulin dose should perform when my blood sugar is higher than it should?

Item 26 Can I adjust my insulin dose when I have a cold or flu?

\section{General Management}

Item 2 Am I confident in my ability to deal with diabetes?

0.76

$\underline{\text { Item } 3}$ Do I feel secure in using my knowledge about diabetes,

0.76 including daily treatment?

Item 4 Do I believe I can follow the diabetes routines every day?

0.571

0.741

Item 12 Can I not perform the regular physical activity? in the mood.

Item 14 Do I know when I should call (search) to my doctor

Item 15 Can I apply the recommended daily lotion on my feet?

Item 16 Can I test my blood sugar or urine when I am away from home?

Item 17 Can I recognize when my blood sugar is too high?

Item 18 Can I recognize when my blood sugar is too low?

Item 19 Do I do blood or urine sugar testing more often than usual when I'm sick?

Item 20 Can I apply insulin using the correct technique?

Item 27 Am I sure, that the treatment of diabetes does not of diabetes, even when changes in my daily routine (some change what I am used to doing every day)? 
Table 3

Spearman's correlation coefficients between the domains and total score of the Brazilian version of the Insulin Management Diabetes Self-Efficacy Scale - IMDSES and domains of the Summary of Diabetes Self-Care Activities Measures - SDSCA $(n=127)$.

\begin{tabular}{|c|c|c|c|c|c|c|}
\hline \multirow{3}{*}{ IMDSES domains } & \multicolumn{6}{|c|}{ SDSCA - domains } \\
\hline & $\begin{array}{c}\text { General } \\
\text { Diet }\end{array}$ & $\begin{array}{c}\text { Specific } \\
\text { Diet }\end{array}$ & $\begin{array}{l}\text { Physical } \\
\text { Activity }\end{array}$ & $\begin{array}{c}\text { Glucose } \\
\text { monitoring }\end{array}$ & $\begin{array}{l}\text { Feet } \\
\text { Care }\end{array}$ & Medication \\
\hline & $r^{*}\left(p^{* *}\right)$ & $r(p)$ & $r(p)$ & $r(p)$ & $r(p)$ & $r(p)$ \\
\hline Diet & $\begin{array}{c}-0.40 \\
<0.0001\end{array}$ & $\begin{array}{c}-0.27 \\
(<0.0001)\end{array}$ & $\begin{array}{l}-0.10 \\
(0.26)\end{array}$ & $\begin{array}{l}-0.18 \\
(0.03)\end{array}$ & $\begin{array}{l}-0.29 \\
(<0.0001)\end{array}$ & $\begin{array}{c}-0.26 \\
(<0.0001)\end{array}$ \\
\hline Insulin & $\begin{array}{l}0.05 \\
(0.52)\end{array}$ & $\begin{array}{l}0.05 \\
(0.51)\end{array}$ & $\begin{array}{l}-0.18 \\
(0.03)\end{array}$ & $\begin{array}{l}-0.07 \\
(0.41)\end{array}$ & $\begin{array}{l}-0.24 \\
(<0.0001)\end{array}$ & $\begin{array}{r}0.02 \\
(0.77)\end{array}$ \\
\hline $\begin{array}{l}\text { General } \\
\text { management }\end{array}$ & $\begin{array}{c}-0.26 \\
(<0.0001)\end{array}$ & $\begin{array}{l}-0.22 \\
(0.01)\end{array}$ & $\begin{array}{c}0.24 \\
(<0.0001)\end{array}$ & $\begin{array}{c}-0.17 \\
(0.04)\end{array}$ & $\begin{array}{l}-0.33 \\
(<0.0001)\end{array}$ & $\begin{array}{l}-0.07 \\
(0.43)\end{array}$ \\
\hline Total IMDSES & $\begin{array}{c}-0.29 \\
(<0.0001)\end{array}$ & $\begin{array}{l}-0.22 \\
(0.01)\end{array}$ & $\begin{array}{c}-0.23 \\
(<0.0001)\end{array}$ & $\begin{array}{l}-0.21 \\
(0.01)\end{array}$ & $\begin{array}{l}-0.39 \\
(<0.0001)\end{array}$ & $\begin{array}{l}-0.17 \\
(0.05)\end{array}$ \\
\hline
\end{tabular}

${ }^{*} r=$ Spearman correlation coefficients; ${ }^{* *} p=p$-value.

\subsection{Criterion Validity}

Criterion validity was tested by correlational evidence between scores of the domains and the Total score of IMDSES and serum levels of HbA1c. Weak positive magnitude correlations were found between the score of the General Management domain $(r=0.22 ; p=0.02)$ and the Total score $(r=0.22 ; p=0.02)$ of IMDSES and the average value of $\mathrm{HbA} 1 \mathrm{c}$.

\section{DISCUSSION}

The aim of this study was to deepen the assessment of the psychometric properties of the Brazilian version of IMDSES through its use in patients with T2DM. Regarding the analysis of the practicability of IMDSES, it is important to note that the original scale was constructed to be selfadministered and in this study, considering the low socioeconomic status and poor education of the study group (mean of 6.1 years of education), it was chosen for its application through inter-views. Thus, the evaluation of the practicability of IMDSES showed a moderate time length for application in interview format (21.7 minutes). Previous study ${ }^{24}$ conducted with 181 patients with
DM, in which $54 \%$ had up to 12 years of study, the short-form IMDSES was easily filled, implying a low cost to the respondent, although it has not been described the average time of application. In other studies using the instrument, the practicability has not been evaluated.

As for acceptability, the results show good acceptance of the instrument since all the patients responded to all of the items. However, a high percentage of responses "Does not apply/not applied was recorded to items 14 and 15, which belongs to the domain of General Management of the Brazilian version of the IMDSES. This find-ing may indicate the need for greater investment in the education of T2DM patients regarding their treatment, since $47.7 \%$ of patients enrolled had a diagnosis of peripheral neuropathy.

It has been found a ceiling effect on insulin domain, i.e., $18.9 \%$ of participants scored the best possible results of the scale in this domain. The same finding was observed previously ${ }^{24}$ for the domains of Physical activity and Routine variables, which are encompassed in the domain of General Management in the Brazilian version of IMDSES.

As for reliability, this study demonstrated satisfactory internal consistency for all the domains and to the Total Score of IMDSES, support- 
ing the original findings of the study that also used the IMDSES of 28 items, finding satisfactory Cronbach's alpha for the Total Score $(\alpha=0.82)$ and for most of its domains. Previous studies using modified versions of IMDSES balanced by the number of items also showed satisfactory inter-nal consistency for all the domains and the Total Score. ${ }^{17,18,25}$ In our study, analysis of item-total correlation and Cronbach's alpha if the item deleted showed little meaning for the value of Cronbach's alpha of Diet domain with 0.71 to 0.73 to the exclusion of items 1 and 10. It was also noted slight increase of $\alpha$ in the General Management domain with 0.76 excluding items of 12 and 27 and most importantly increased Cronbach's alpha of 0.78 to 0.81 if deleted item 13. In the

study of Rapley, Passmore, and Phillips, ${ }^{24}$ they have also shown that the items 12 and 13 (both related to exercise) had a lower value of Cronbach's alpha. In the study of Gastal, Pinheiro, and Vazquez, ${ }^{17}$ items 12 and 13 were also excluded, however, because of their low factor loadings $(<0.30)$ in the factor analysis.

Like previous history studies, ${ }^{16,18}$ the correlations between the constructs of self-efficacy and self-care by applying the respective scales were of weak to moderate magnitude, confirming the construct validity of the Brazilian version of IMDSES. Although the humble findings given the size of correlations, it is relevant to highlight the capacity of this instrument to correctly measure such a complex construct as self-efficacy; which can be much more defying among a low literacy sample such as ours - this evidence can not be mistreated, since this sample probably represents most of Brazilian population. This relationship supports the underlying assumption that confidence of the individual in their abilities to perform a given behavior determines what behavior it can engage and how intense and lasting will be the engagement to deal with the challenges to achieving the expected results.

Criterion validity was assessed by correlation with $\mathrm{HbA1C}$, which reflects the average blood glucose control in the three months prior to its acquisition, was supported in this study by weak magnitude of correlations between the domain General Management and Total Score of the Brazilian version of IMDSES and HbA1c. Gastal,
Pinheiro, and Vazquez ${ }^{17}$ found a significant association between self-efficacy level in Insulin domain of the Brazilian version of IMDSES 20 items and the level of HbA1c (ANOVA) and a linear trend that the higher self-efficacy, the lower level of HbA1c. In the study by Hurley \& Harvey ${ }^{16}$ found an association between all domains of original IMDSES and the level of HbA1c. Despite the small correlations, it is noticeable that the questionnaire was able to demonstrate correlations with such a strong variable such as $\mathrm{HbA} 1 \mathrm{c}$, since relations with objective measures are considered as the most strong relations an instrument may demon-strate. We must highlight that HbA1c is one of the best choices to assess self-efficacy behavior for insulin use, since it is the best serum variable to evaluate glucose levels - which reflect patient's adherence to T2DM as a whole - including medi-cation (as insulin), diet and physical activity. HbA1c has been used in guidelines worldwide as an ex-cellent marker to adherence.

In the literature, there is no consensus on the magnitude of the relationship between the level of self-efficacy and HbA1c. In a recent study, $\mathrm{HbA1c}$ levels were significantly correlated with the degree of self-efficacy among type 1 diabetics, but not among individuals with type 2 diabetes, suggesting that the factors that contribute to selfefficacy in diabetes patients with type 1 and type 2 are probably different. ${ }^{26}$

As for the limitations, we must recognize that the alteration in the way the instrument was delivered (self-applied to interview) may modify the way participants respond to the questionnaire - although this alteration is supported elsewhere. ${ }^{17}$ Besides, limitations regarding the use of self-reported measures must be taken into account, as bias of social desirability (in which the respondent answers what he believes the interviewer expects to hear) and memory.

In summary, the results of this study point to the reliability and partially support convergent construct and criterion validity of the Brazilian version of IMDSES when applied to T2DM patients. It is expected that the findings of this research contribute to the psychometric refinement of the Brazilian version of IMDSES 28-items with a view to their future use in assessing the impact of nursing interventions on patient's care diabetic insu- 
lin applicant types 1 and 2 . It is recommended to carry out further studies with sample expanded to assess the validity of known groups (such as good glucose control $x$ poor glucose control, us-ing $\mathrm{HbA1c}$ ) and the responsiveness of the Brazil-ian version of the IMDSES 28-items in T2DM. It is also suggested the replication of this study among subjects from different socioeconomic status to confirm its practicability and acceptability.

\section{CONCLUSION}

The results of this study indicate that the Brazilian 28-item IMDSES requires a moderate time of application and have good acceptability when applied to T2DM patients with low literacy. It seems that the instrument has a potential to measure worsens and improves in self-efficacy, since no relevant ceiling or floor effects were found. The findings point to satisfactory reliability regarding internal consistency and convergent construct validity. Predictive criterion validity tested by the relationship with serum levels of $\mathrm{HbA1c}$ was partially supported. The availability of a reliable and valid instrument is an essential tool for evaluating the effectiveness of nursing interventions aimed at optimizing self-efficacy of T2DM outpatients in the management of their treatment.

\section{REFERENCES}

1. Introduction. Diabetes Care. 2017;40(Suppl 1):S1-S2.

2. Bandura A. Social foundations of thought and action: A social cognitive theory. New Jersey, NJ: Prentice Hall.; 1986. 39-453 p.

3. Bandura A. Human agency in social cognitive theory. Am Psychol. 1989;44:1175-84.

4. Ahmad Sharoni SK, Abdul Rahman H, Minhat HS, ShariffGhazali S, Azman Ong MH. The effects of self-efficacy enhancing program on foot self-care behav-iour of older adults with diabetes: A randomised con-trolled trial in elderly care facility, Peninsular Malaysia. PLoS One. 2018; 13:e0192417.
5. Huang L, Li L, Zhang Y, Li H, Li X, Wang H. Self-efficacy, medication adherence, and quality of life among people living with HIV in Hunan Province of China: a questionnaire survey. J Assoc Nurses AIDS Care. 2013;24:145-53.

6. Zhang X, Zhan Y, Liu J, Chai S, Xu L, Lei M, et al. Chinese translation and psychometric testing of the cardiac self-efficacy scale in patients with coronary heart disease in mainland China. Health Qual Life Outcomes. 2018; 16:43.

7. Tharek Z, Ramli AS, Whitford DL, Ismail Z, Mohd Zulkifli M, Ahmad Sharoni SK, et al. Relationship between selfefficacy, self-care behaviour and gly-caemic control among patients with type 2 diabetes mellitus in the Malaysian primary care setting. BMC Fam Pract. 2018;19:39.

8. Lee $Y$ J, Shin $S$, Wang RH, Lin $K D$, Lee $Y L$, Wang $Y H$. Pathways of empowerment perceptions, health literacy, self-efficacy, and self-care behaviors to glycemic control in patients with type 2 diabetes mellitus. Patient Educ Couns. 2016;99:287-94.

9. Lee EH, van der Bijl J, Shortridge-Baggett LM, Han SJ, Moon SH. Psychometric Properties of the Diabe-tes Management Self-Efficacy Scale in Korean Pa-tients with Type 2 Diabetes. Int J Endocrinol. 2015; 2015:780701.

10. Chang SJ, Song M, Im EO. Psychometric evaluation of the Korean version of the Diabetes Self-efficacy Scale among South Korean older adults with type 2 diabetes. J Clin Nurs. 2014;23(15-16):2121-30.

11. King DK, Glasgow RE, Toobert DJ, Strycker LA Estabrooks PA, Osuna D, et al. Self-efficacy, prob-lem solving, and social-environmental support are associated with diabetes self-management behaviors. Diabetes Care. 2010;33:751-3.

12. Erol O, Enc N. Hypoglycemia Fear and Self-efficacy of Turkish Patients Receiving Insulin Therapy. Asian Nurs Res (Korean Soc Nurs Sci). 2011;5:222-8.

13. Sangruangake $M$, Jirapornkul $C$, Hurst $C$. Psycho-metric Properties of Diabetes Management Self-Ef-ficacy in Thai Type 2 Diabetes Mellitus Patients: A Multicenter Study. Int J Endocrinol. 2017; 2017: 2503156.

14. Van Allen J, Noser $A E$, Littlefield $A K$, Seegan $P L$, Clements M, Patton SR. Measuring Self-Efficacy in the Context of Pediatric Diabetes Management: Psychometric Properties of the Self-Efficacy for Diabetes Scale. J Pediatr Psychol. 2018;43:143-51.

15. Pace AE, Gomes LC, Bertolin DC, Loureiro HMAM, Bijl JV, Shortridge-Baggett LM. Adaptation and vali-dation of the Diabetes Management Self-Efficacy Scale to Brazilian Portuguese. Rev latinoam enferm. 2017;25:e2861.

16. Hurley, C. A, Harvey RM. The insulin management diabetes self-efficacy scale. In: Strickland OL, Dilorio C, editors. The Measurement of Clinical and Educations Nursing Outcomes. New York, NY: Springer Publishing Commpay.; 1990. p. 526-726. 
17. Gastal DA, Pinheiro RT, Vazquez DP. Self-efficacy scale for Brazilians with type 1 diabetes. Sao Paulo Med J. 2007; 125:96-101.

18. Hurley AC, Shea CA. Self-efficacy: strategy for enhancing diabetes self-care. Diabetes Educ. 1992;18:14650.

19. Toobert DJ, Hampson SE, Glasgow RE. The sum-mary of diabetes self-care activities measure: re-sults from 7 studies and a revised scale. Diabetes Care. 2000;23:943-50.

20. Michels MJ, Coral MH, Sakae TM, Damas TB, Furlanetto LM. [Questionnaire of Diabetes Self- Care Activities: translation, cross- cultural adaptation and evaluation of psychometric properties]. Arq Bras Endocrinol Metabol. 2010;54:644-51.

21. Bennet SJ, Oldridge NB, Eckert GJ, Embree JL, Browning $\mathrm{S}$, Hou $\mathrm{N}$, et al. Discriminant properties of commonly used quality of life measures in heart fail-ure. Qual Life Res. 2002;11:349-59.
22. Nunnaly JC. Psychometric theory. New York: McGrawHill, 1978.

23. Fishbein M, Ajzen I. Understanding attitudes and predicting social behavior. Englewood Cliffs: Prentice Hall, 1980.

24. Rapley P, Passmore A, Phillips M. Review of the psychometric properties of the Diabetes Self-Effi-cacy Scale: Australian longitudinal study. Nurs Health Sci. 2003;5:289-97.

25. Pauley T, Gargaro J, Chenard G, Cavanagh H, McKay SM. Home-based diabetes self-management coach-ing delivered by paraprofessionals: A randomized controlled trial. Home Health Care Serv Q. 2016;35:137-54.

26. Sacco WP, Bykowski CA. Depression and hemoglobin A1c in type 1 and type 2 diabetes: the role of selfefficacy. Diabetes Res Clin Pract. 2010;90:141-6. 